\title{
Remote Learning during a Pandemic: \\ A Retrospect and Prospect
}

\author{
Wei Chin Wong* and Xun Wang \\ BNU-HKBU United International College
}

\begin{abstract}
Both educators and students in schools across the globe have faced unprecedented and sweeping changes to teaching and learning due to the 2019 coronavirus disease pandemic (COVID-19). This paper focuses on the case of remote learning in BNU-HKBU United International College (UIC) during the spring semester 2019/2020. Based on two surveys conducted respectively at the beginning and the end of the semester on students' experiences with online learning, this paper explores and summarizes students' retrospective views on several aspects of remote learning, including technical difficulties, potential challenges and drawbacks of online courses across different provinces in Mainland China. In doing so, this paper aims to depict the paradigm of how students adjusted their study habits for independent learning during the coronavirus lockdown.
\end{abstract}

Keywords: COVID-19 pandemic, remote learning, independent learning, online learning

*Corresponding author: Wei Chin Wong. E-mail: weichinwong@uic.edu.cn 


\section{A Look Back: Remote Learning through a Pandemic}

Since late January 2020, both educators and students in schools across Mainland China have faced sweeping and unprecedented changes to teaching and learning due to the sudden outbreak of coronavirus disease (COVID-19). To better combat the coronavirus pandemic, the central government immediately imposed a pandemic lockdown in Wuhan and other cities in Hubei right after all domestic transportation such as buses, trains, airplanes, and ferries were suspended. When we saw the disease that could close public facilities and institutions spreading across the nation, we realized that our daily activities and life on campus would be severely affected and it would be vital to find new ways of delivering education to our students during these times of disruption. In response to the public health crisis and widespread disruption, the emergency shift to remote teaching for the upcoming spring semester was justified as an exceptional measure among Chinese universities in Mainland China.

Like many other teaching faculties in BNU-HKBU United International College (UIC), I have been suddenly thrown into the world of remote teaching without preparation since early February. As someone whose work centers on teaching, I knew that it was not the time to wait and see what resources or training will be recommended for both educators and students. To better engage students to obtain critical information that I needed to help continue to educate my students, initial online surveys via the iSpace/Moodle platform were conducted for all three of my undergraduate courses, i.e., History of Traditional Southeast Asia, China in Western Perspectives, and Migration in World History, after I provided preliminary training classes remotely to the students.

Questionnaires were distributed at the end of Week Zero (February 9 to 13, 2020), during which UIC teaching faculties and students were to acquire vital skills to facilitate remote teaching and learning. The following four issues were examined in this initial questionnaire:

(a) Students were asked to specify their current location.

(b) Students were asked to describe his/ her impression or experience in general about remote teaching or online courses in China.

(c) Students were asked if they have encountered any problems with the online environment, such as weak internet connectivity, uploading problem, the time lag in the live broadcast, access to our school's IT 
support, and other issues.

(d) They were asked to choose which video conferencing software they preferred between Panopto Cloud and Zoom.

From February 12 to 13, 2020, eighty-two questionnaires were distributed and filled in anonymously by the students who enrolled in my courses. The majority of students responded promptly to the questionnaire, with $79 \%$ returning it on the day it was made available and a final completion rate of $85 \%$.
As shown in Figure 1 below, in this initial survey, 33 percent of the students reported problems in connectivity and time lag issues during their first week of classes, whereas 12 to 15 percent of them had accessing problems with iSpace/Moodle, and 8 percent of them could not get timely assistance from our IT department. At this stage, relatively minor impacts of these issues on students' learning experiences were revealed, as Week Zero was used as test-run and the course work requirements were not yet intensive.

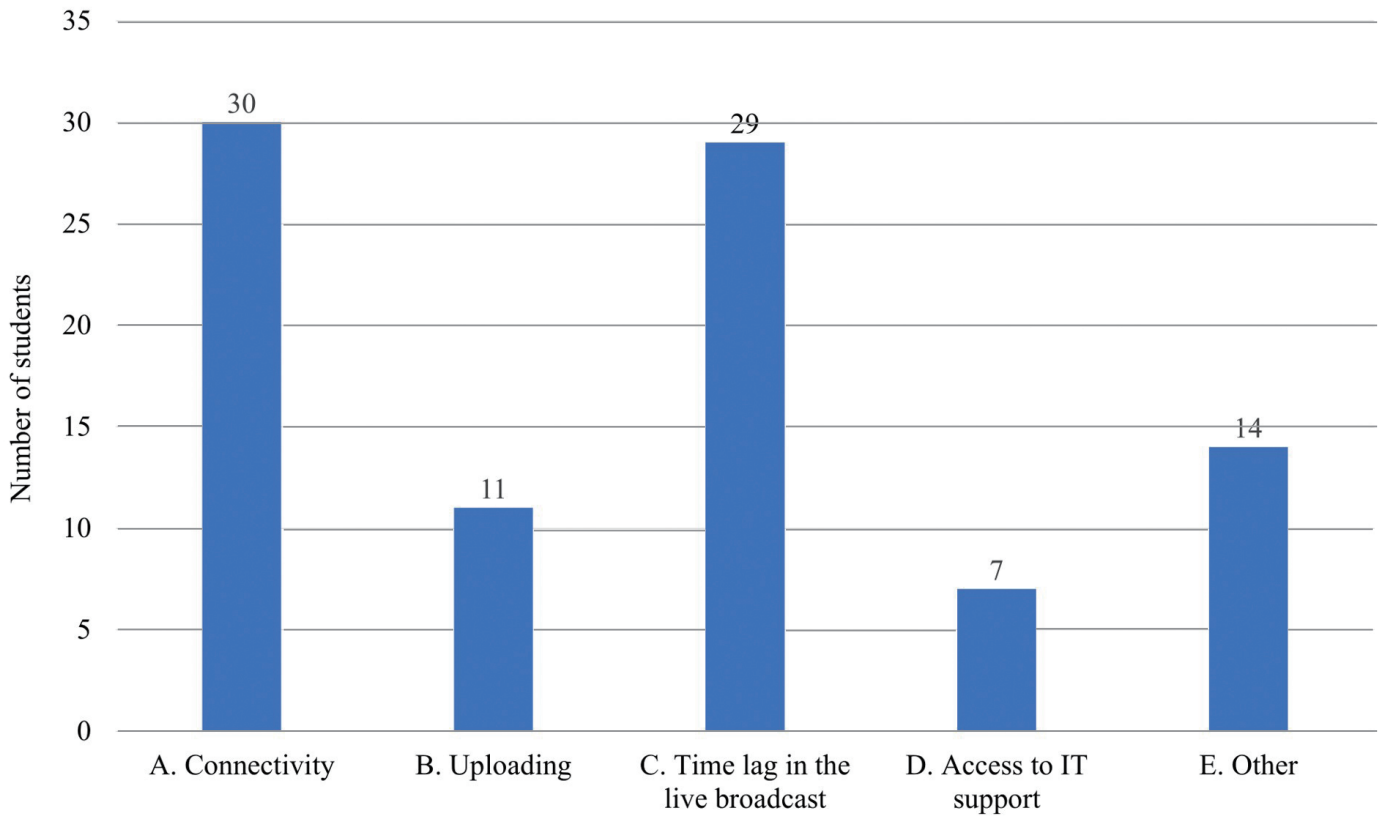

Figure 1. Students' problems with the online environment in week zero (Feb. 10-14, 2020).

In addition, the results show that students had obviously different attitudes towards the two most commonly used online teaching platforms in UIC during the 
Week Zero. Panopto Cloud was officially assigned by college authorities as the major platform for online teaching. However, there were less than 8 percent of students willing to adopt it as their primary conferencing tool. By contrast, Zoom was utilized as an alternative for Panopto Cloud by lecturers who had difficulties in accessing the Panopto Cloud due to either their location or internet service. The latter one was preferred by 89 percent of the students as their primary video conferencing tool for their online classes in the upcoming weeks.

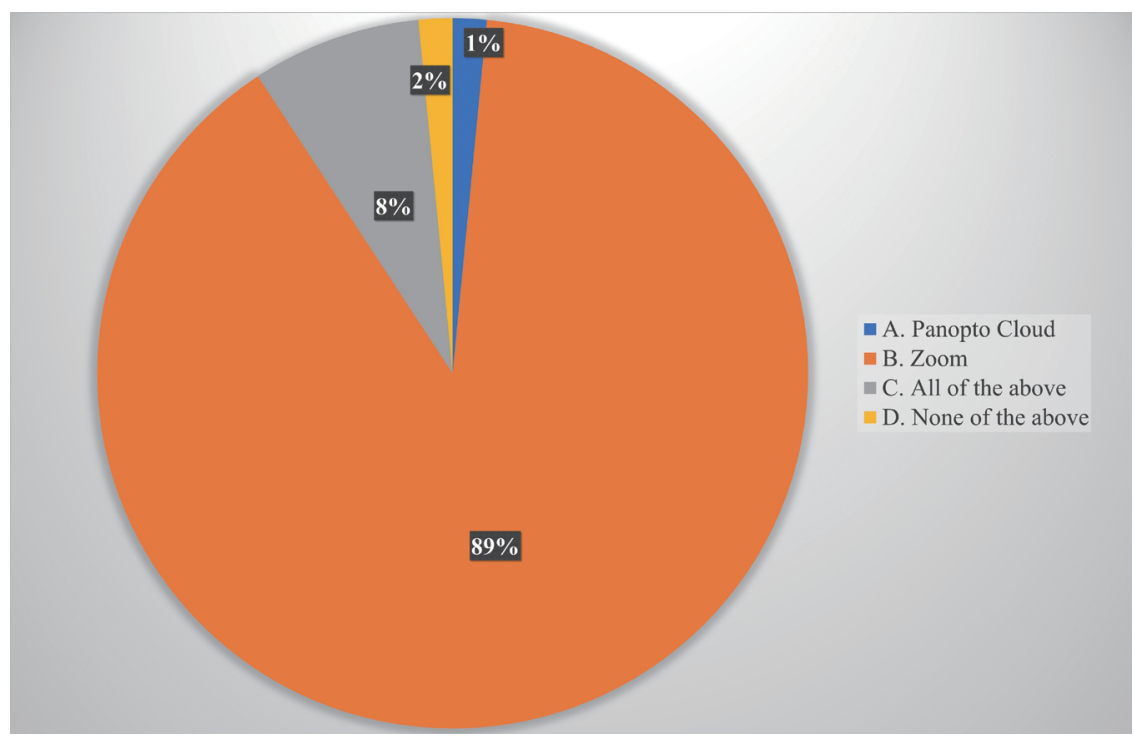

Figure 2. Students' preferences toward Panopto cloud and zoom.

Despite challenges, many students were looking forward to learning their courses remotely through online platforms. In the open-ended question "Describe your experience in general about the online courses in UIC", although some students were reluctant to online classes, most of them embraced the new experience. Some of the positive and negative responses concerning the general impression or experience of remote teaching are as follows:

The positive feedback toward remote teaching among our students might be closely related to the digitalization of everyday life. It has been suggested that a new generation who were born after 2000 has recently appeared all over the world, commonly and variously known as "N-Gen" or "net-generation" (network 
Table 1

The Positive and Negative Responses from Students in the Initial Survey

\begin{tabular}{ll}
\hline \multicolumn{1}{c}{ Positive feedbacks } & \multicolumn{1}{c}{ Refusals } \\
\hline $\begin{array}{l}\text { "New and exciting!" } \\
\text { "Interesting!" }\end{array}$ & "Not as efficient as in classrooms." \\
"It is convenient and useful." & "Not so convenient (as face-to-face teaching)." \\
\hline "It was really good and stable & \\
enough." \\
"It is special." \\
"Amazing!" \\
"Perfect!" \\
"Acceptable." \\
"Smooth and satisfied."
\end{tabular}

generation), "generation D" (digital generation) or "millennials" (Lebedko, 2014, p. 31). The new generation that has grown up on the Internet technologies, as Shuter (2012, p. 219) pointed out, are more flexible and readily accepted the changes from "face-to-face encounters" to "instantaneous communication with others" regardless of geo-political boundaries, time or space. Some researchers also suggested that the new generation is more capable of recognizing significant social media changes, producing new public fora or webpage for hosting multimodal spaces of contact on a scale of many-to-many communication (Pfisher \& Soliz, 2011, p. 246). Since the last decade, the net-generation has been depicted generally as "top young performers", "highly technological savvy", "use a wide range of media and technology to connect with others", "hungry for knowledge", and as a generation who want to "have fun at work" (Cheese, 2008). In other words, our students are familiar with the Internet technology and well-adopted to the online communication. To succinctly examine whether the new characteristics mentioned above were helpful to impact remote teaching strategies across all courses in UIC positively, further surveys were conducted at the end of the semester. In doing so, this paper explored the post-mortem feedback from students after they had experienced nearly four months of intensive online learning. 


\section{Methodology: Students' Feedbacks about Online Learning during the Pandemic}

The research methods of this paper may be divided into two stages. Both stages combined quantitative and qualitative research, through which numerical and textual data were collected simultaneously (Babbie, 2006, p. 23-25).

At the earlier stage, as discussed above, the preliminary survey was conducted at the end of Week Zero with students who enrolled in the author's courses. The questionnaire included both multiple-choice questions and open-ended questions to obtain numerical and textual data. ${ }^{1}$

At the later stage, a further survey was launched at the end of the semester with a questionnaire that was revised based on the actual practice of online learning over the semester. Information that helped the revision was collected through the author's interviews with teaching assistants and students, particularly with those who were acquainted with remote teaching, as witnesses of difficulties and active participants of online courses throughout the spring semester, and as they would have a good understanding of why the research was being conducted. The revised questionnaires contained some multiple-choice questions, in a similar style to those asked in the earlier survey, but they also contained more open-ended questions that took participants longer to complete, which suggests that the results we collected were representative and were not biased by the differential response rates. ${ }^{2}$

In addition, before conducting the questionnaire survey for the second stage, two pilot written questionnaires were conducted with one of the author's teaching assistants and students, Clare Zhu and Wang Xun (who is also the second author of this research paper), in order to get feedback and to see whether the questions designed in the survey for the second stage were suitable and sufficient. After listening to and evaluating the pilot opinions and observations, the questions in the further surveys were revised again to better serve the research purpose of examining students' online learning experience throughout the semester.

\section{Questionnaire}

This revised questionnaire was distributed and sent via school e-mail to the stu-

\footnotetext{
${ }^{1}$ For the original questionnaire, please refer to appendix 1 at the end of this paper.

${ }^{2}$ The second set of questionnaires are reproduced in appendix 2 at the end of this paper.
} 
dents of the author's three courses on June 10. In addition to students who enrolled in the courses in the Spring semester 2019/2020, former students of these three courses were also invited. Meanwhile, the questionnaire was also circulated via WeChat from June 10 to 16 , in order to research a larger range of UIC students. During this survey period (June 10 to 16 , 2020), 151 responses were collected from students of all four academic divisions in UIC, namely, Division of Businesses and Management (DBM), Division of Culture and Creativity (DCC), Division of Humanities and Social Sciences (DHSS), and Division of Science and Technology (DST).

This second set of questionnaires consisted of two sections and seven questions. In Section I, necessary information about the respondents was collected, including the name, which year of the study in UIC, gender, academic division, and their consent whether to keep the feedback as "open" or "anonymous". The results show that, as shown in Table 1 below, there were 40 (26 percent), 33 (22 percent), 53 ( 35 percent), and 25 (17 percent) respondents from four different divisions. Table 1 also reveals that the sex ratio of male and female respondents is close to $2: 5$, which is similar to the male-female proportion of student enrollment in our college. Besides, the results further show that most of our respondents were undergraduate students, including Freshman (17 percent), Sophomore (38 percent), Junior (13 percent), and Senior (48 percent), and there is only one postgraduate student answered the questionnaire.

\section{Table 2}

\section{The Data of 151 Respondents}

\begin{tabular}{ccccccccccc}
\hline \multicolumn{1}{c}{ Gender } & \multicolumn{1}{c}{ Year of Study at UIC } & \multicolumn{5}{c}{ Division } \\
\hline Male & Female & Freshman & Sophomore & Junior & Senior & Postgrad & DBM & DCC & DHSS & DST \\
44 & 107 & 25 & 57 & 20 & 48 & 1 & 40 & 33 & 53 & 25 \\
$29 \%$ & $71 \%$ & $17 \%$ & $38 \%$ & $13 \%$ & $32 \%$ & $1 \%$ & $26 \%$ & $22 \%$ & $35 \%$ & $17 \%$ \\
\hline
\end{tabular}

In Section II, the following four aspects of distance learning were examined:

(a) Students were asked to specify their most frequent location during the semester.

(b) Students were asked to list the online learning platform(s) he/she was using throughout the semester. 
(c) The students were asked to rate their level of satisfaction and describe his/her online learning experiences throughout the semester, including problems and challenges encountered and the memorable moments he/she had in different courses.

(d) Students were invited to provide solution(s) and/or suggestion(s) to improve the online learning process.

Compared with the questionnaire distributed at the end of Week Zero, the revised questionnaire included a new platform, WeChat Work, according to the actual teaching and learning practices in our school. Meanwhile, more open-ended questions were added to the questionnaire to collect retrospective views from the students. For instance, they were asked to describe the most significant challenge(s) they have encountered and the most memorable experience(s) they had when learning remotely during a pandemic.

\section{Results and Analysis}

As Figure 3 demonstrates, during the distance learning period, the respondents were attending online courses respectively from 21

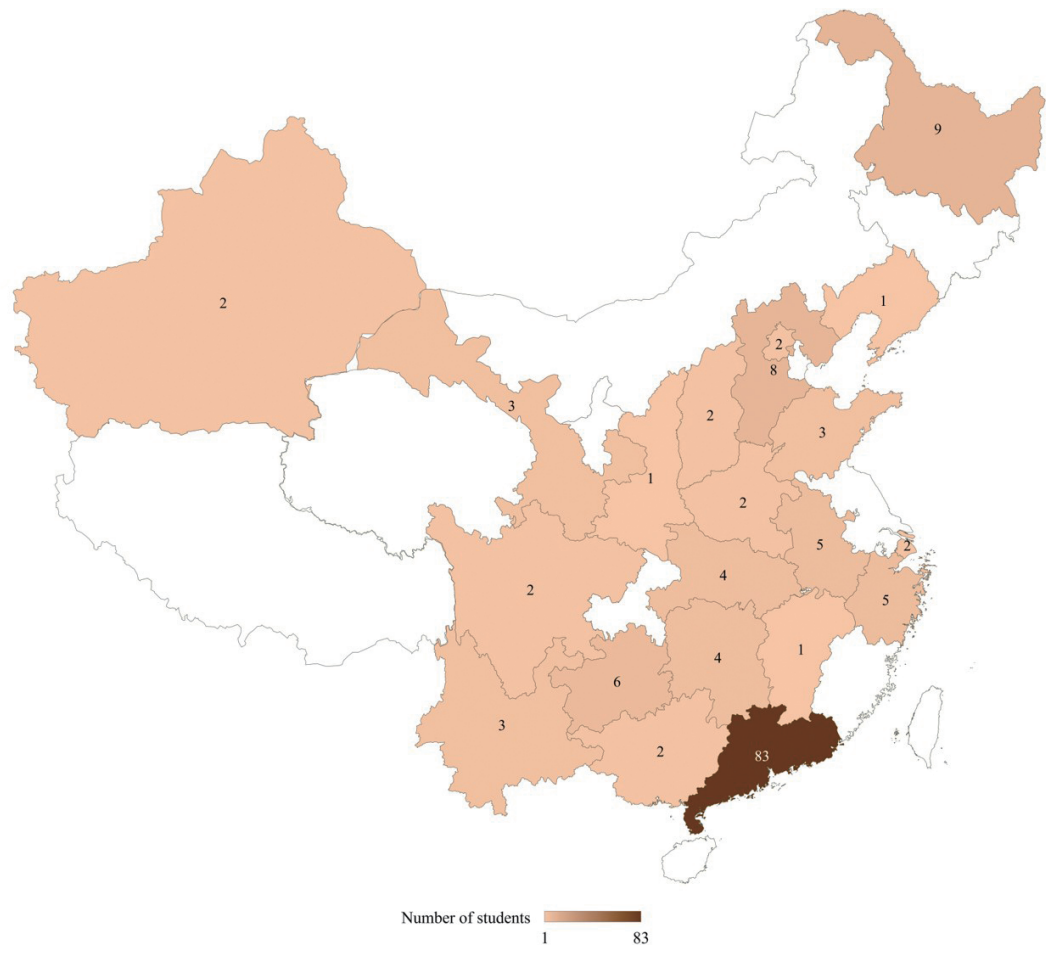

Figure 3. The distribution of students across mainland China during the remote learning period (Feb. 10- May 20, 2020). 
14 Wei Chin Wong \& Xun Wang

provinces and municipalities across Mainland China, including Anhui, Henan, Heilongiiang, Shandong, Hubei, Beijing, Guizhou, Guangxi, Shanghai, Yunnan, Hunan, Zhejiang, Sichuan, Shanxi, Shaanxi, Liaoning, Xinjiang, Jiangxi, Gansu, Hebei, and Guangdong. Among these locations, Guangdong homed the largest number of students, accounting for 55 percent of the respondents. In addition, one of the responding students was residing in Hong Kong during the semester.

Table 2 below illustrates the technical problems encountered by students from different learning locations. Among the places

\section{Table 3}

\section{Technical Problems that Students across China Encountered}

\begin{tabular}{|c|c|c|c|}
\hline Location & Connectivity & Uploading & Time lag in the live broadcast \\
\hline Anhui & $\sqrt{ }$ & $\sqrt{ }$ & $\sqrt{ }$ \\
\hline Henan & $\sqrt{ }$ & & \\
\hline Heilongjiang & $\sqrt{ }$ & $\sqrt{ }$ & $\sqrt{ }$ \\
\hline Shandong & $\sqrt{ }$ & & \\
\hline Hubei & $\sqrt{ }$ & & $\sqrt{ }$ \\
\hline Beijing & $\sqrt{ }$ & $\sqrt{ }$ & $\sqrt{ }$ \\
\hline Guizhou & $\sqrt{ }$ & $\sqrt{ }$ & $\sqrt{ }$ \\
\hline Guangxi & $\sqrt{ }$ & & $\sqrt{ }$ \\
\hline Shanghai & $\sqrt{ }$ & & \\
\hline Yunnan & $\sqrt{ }$ & $\sqrt{ }$ & $\sqrt{ }$ \\
\hline Hunan & $\sqrt{ }$ & $\sqrt{ }$ & $\sqrt{ }$ \\
\hline Zhejiang & $\sqrt{ }$ & $\sqrt{ }$ & $\sqrt{ }$ \\
\hline Sichuan & $\sqrt{ }$ & $\sqrt{ }$ & $\sqrt{ }$ \\
\hline Shanxi & $\sqrt{ }$ & $\sqrt{ }$ & $\sqrt{ }$ \\
\hline Shaanxi & & $\sqrt{ }$ & \\
\hline Liaoning & $\sqrt{ }$ & & $\sqrt{ }$ \\
\hline Xinjiang & $\sqrt{ }$ & $\sqrt{ }$ & $\sqrt{ }$ \\
\hline Jiangxi & $\sqrt{ }$ & & $\sqrt{ }$ \\
\hline Gansu & $\sqrt{ }$ & $\sqrt{ }$ & $\sqrt{ }$ \\
\hline Hebei & $\sqrt{ }$ & $\sqrt{ }$ & \\
\hline Guangdong & $\sqrt{ }$ & $\sqrt{ }$ & $\sqrt{ }$ \\
\hline Hong Kong SAR & $\sqrt{ }$ & & \\
\hline Total & 21 & 14 & 16 \\
\hline
\end{tabular}


where our students were located, students resided in all locations have had difficulties and other issues with regards to the Internet connectivity, except Shaanxi province. In the meantime, students from Anhui, Heilongjiang, Beijing, Guizhou, Yunnan, Hunan, Zhejiang, Sichuan, Shanxi, Xinjiang, Gansu, Hebei, and Guangdong frequently encountered both uploading and lagging problems when they attended online courses at home during the semester.

As shown in Figure 4, the results indicate that 89 (59 percent) of our students experienced weak Internet connectivity during the entire online learning period. Besides, 49 (32 percent) of them had difficulties submitting assignments and other materials onto the iSpace/Moodle system, and 58 (38 percent) of the students experi- enced time lag problems during their synchronous online lectures. Although the students had sought help and technical advice from our IT department, unfortunately, 26 (17 percent) of the students reported that they were not gaining effective solutions or timely support from our IT department.

During the intensive teaching weeks, unlike in the Week Zero, these issues became annoying and demotivated for students. Many students who suffered from Internet connectivity problems complained that they were repeatedly disconnected from the live meeting room. As a result, these students found themselves missed course content and key points from teachers.

Zoom, iSpace/Moodle, WeChat Work, and Panopto Cloud, as demonstrated in Figure 5, are the four most frequently used

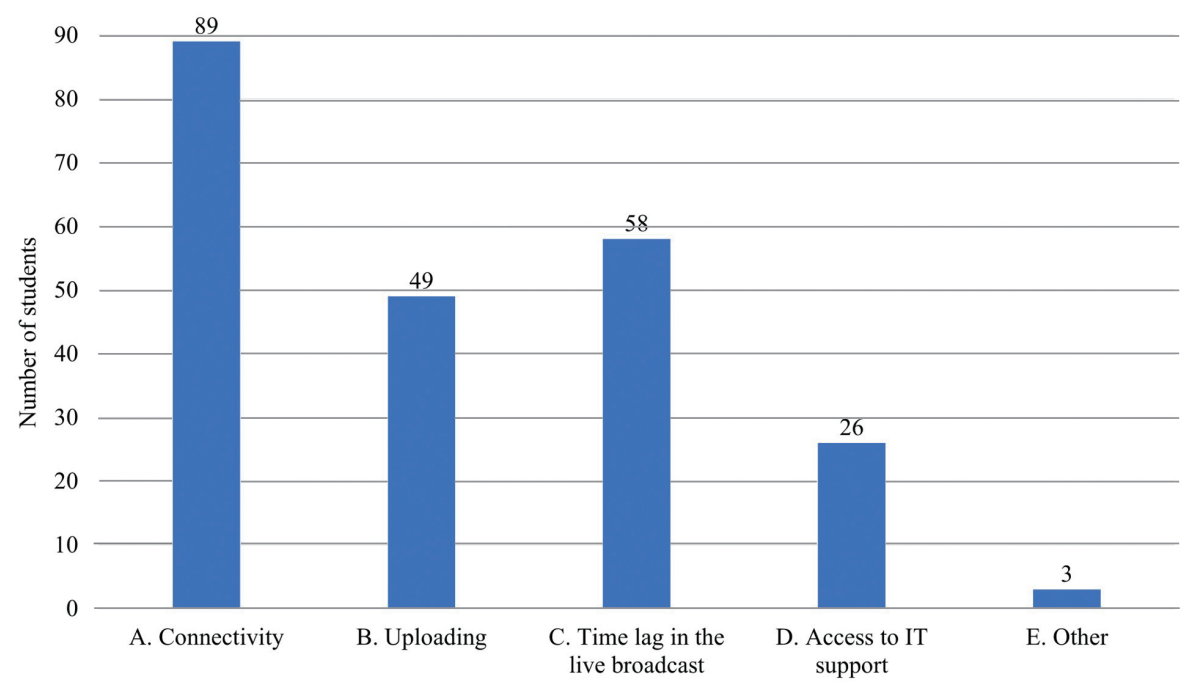

Figure 4. Types of technical problems students encountered during the online courses. 
online teaching platforms in UIC. At the same time, there are also a small number of students were adopting Tencent Meeting, Big Blue Button, and TalkLine as one of their video conferencing tools for their online classes. However, the answers were again reported that iSpace/Moodle and Panopto Cloud are the most unstable platforms among students/users. The results in Figure 5 show that 79 and 55 percent of Panopto Cloud's and iSpace/Moodle's users were having technical problems during the entire semester, which are significantly higher than that of Zoom and WeChat Work.
Despite the fact that Zoom and WeChat Work are the most popular communication tools among students, 39 and 19 percent of students reported that they had also encountered technical issues such as poor connectivity, uploading difficulties, and time lag in transmission during the online courses. Hence, it is not surprising that 88 percent of our respondents have considered Zoom as the most popular online learning platform in the previous spring semester. Panopto Cloud, however, is ranked as the least preferred communication tool among users compared to the

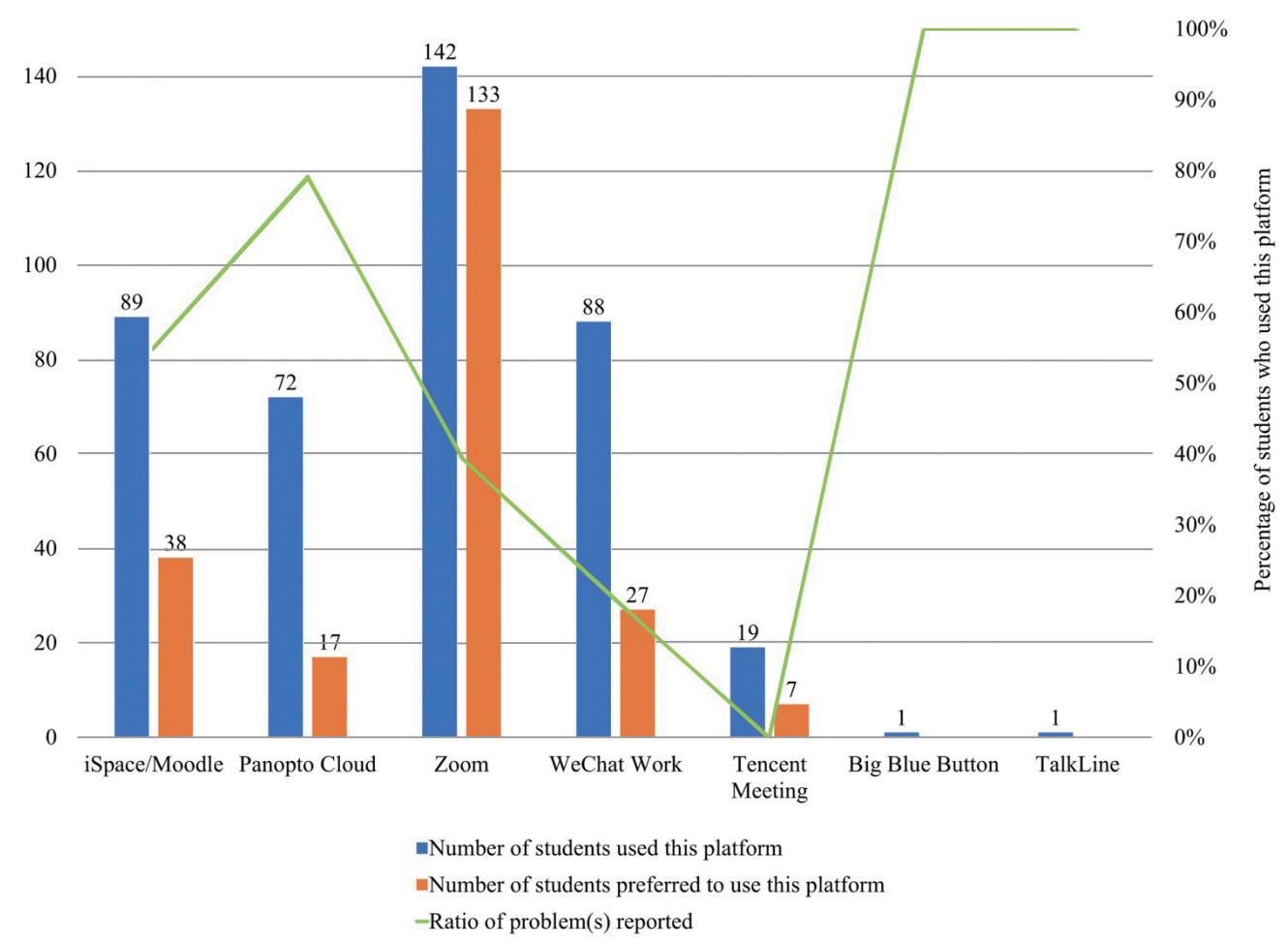

Figure 5. The most and least favorite online teaching tools among UIC students. 
other three major platforms, namely, Zoom, iSpace/Moodle, and WeChat Work. In addition, it is interesting to point out from the results that 25 percent of our students are still preferred to use iSpace/Moodle, and 11 percent of the students would keep Panopto Cloud as their online learning tool regardless of the technical difficulties they may have in the upcoming semester.

Although there were widespread disruptions among teachers and students in the spring semester due to the pandemic, the students' responses indicate that there is 79 percent of them have generally found their online learning experiences above "satisfactory" level (of which include 3 percent highly satisfactory, 36 percent satisfactory, and 40 percent moderately satisfactory). In contrast, 13, 7 and 2 percent of the students were moderately unsatisfied, unsatisfied, and highly unsatisfied with all the online courses they enrolled in throughout the semester.

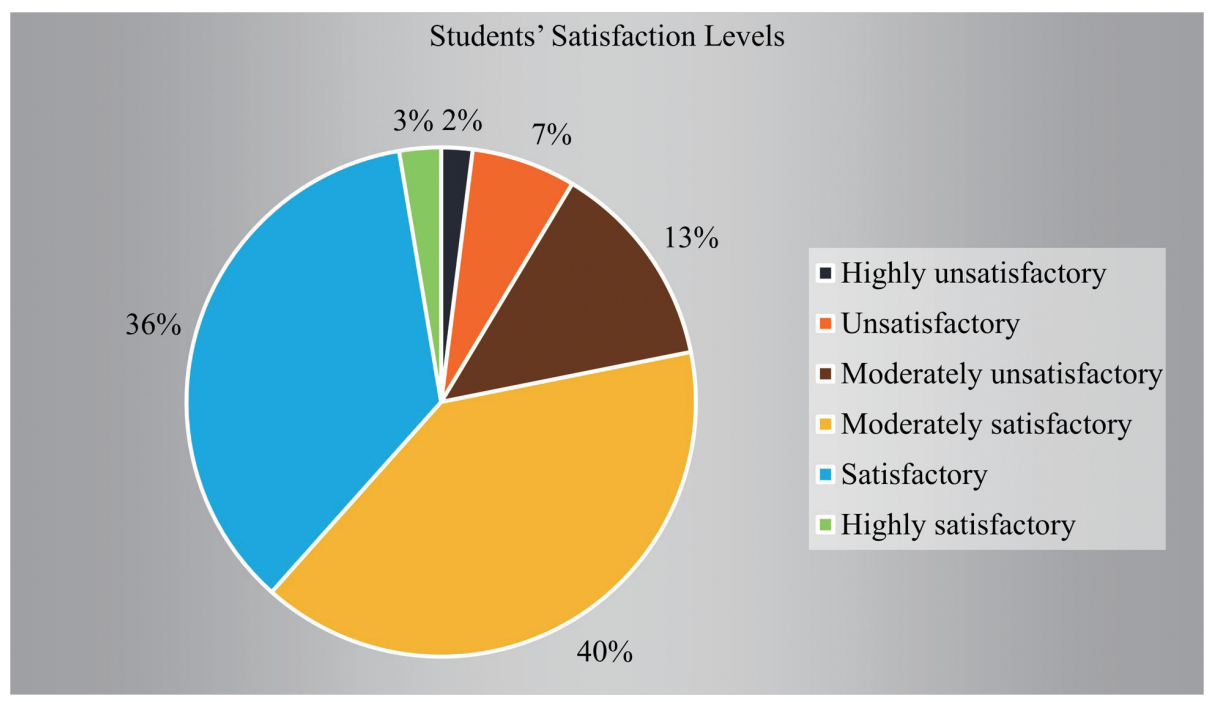

Figure 6. Student satisfaction levels with online courses during the pandemic.

In this further survey, students were also invited to answer the open-ended question of "what was/were the most memorable experience(s) during the semester." The responses indicate that although faced various challenges, students gradually found their own solutions and adapted to remote learning. Accordingly, compared to the responses at the end of Week Zero, this time students appeared to have more confidence in remote learning and most importantly, in their ability to solve the problems that occurred during remote learning. The answers from students are as follows: 
Table 4

Students 'Answers of the Most Memorable Experience

\section{Experience of solving problems}

"My group members and I managed to solve the technical problems and did good rehearsals for our online group presentation."

"It (while doing online presentation) was harder and took more time and effort, but I still think it was a good try and nice experience."

"By watching the reviews, I could understand most of the contents in the classes again and again."

"The open book exams have enhanced my problem-solving skills."

"I can review the pre-recorded videos in doubled speed. It saves my time!"

\section{Experience of trying something new}

"I can study and attend classes even though I was wearing my pajamas."

"Everyone turns (on the) camera while taking exams."

"(I) discussed with group members in Zoom meeting until late at night."

"Teacher asked us to turn on the camera and take (a group) photo for all of us online."

"We have done an online group presentation live on Zoom!"

"(I have completed) seven quizzes (in one course)!"

"I phoned my teacher when it was eleven at night."

"We can have a one-to-one discussion with our teacher."

"We had a group discussion in a breakout room on Zoom."

"We had open-book exams."

"No final exams! Only projects and assignments. It was my first time."

\section{Discussion}

Students demonstrated greater confidence in remote learning as they overcame its problems, which indicates their generation's ability to effectively manage online communication and Internet technology. However, it must be emphasized that all data in the present paper reflects opinions and attitudes toward remote teaching. The obvious question to be asked is the extent to which these opinions are based upon systematic observations, reflect less or no prejudice in favor of courses, and know deeply about remote learning. However, four respondents were honest enough to admit their undesirable learning patterns in the spring semester:

"I need to adjust myself better to adopt 
this teaching method."

"Just be the way you are as usual and do not be lazy."

"Students should improve their self-discipline."

"I think they (the teachers and other students) have done their best, and I should improve myself."

The students' answers again indicate that teachers and students were not prepared for online teaching when the pandemic began. There is no doubt that remote learning is challenging because both teachers and students can quickly feel isolated in the online classroom. Thus, it is critically important for both teachers and students to regularly interacting with each other in a variety of ways, such as by turning on the camera, engaging more in activities like group presentations, discussion forums, and peer-review learning processes. These practices can help create a virtual presence for the online courses and better engage students in the learning process.

Based on the students' responses collected from the questionnaires, the following Figure 7 was created to conclude about the "evolving" independent learning process that occurred among each individual student during the pandemic. ${ }^{3}$

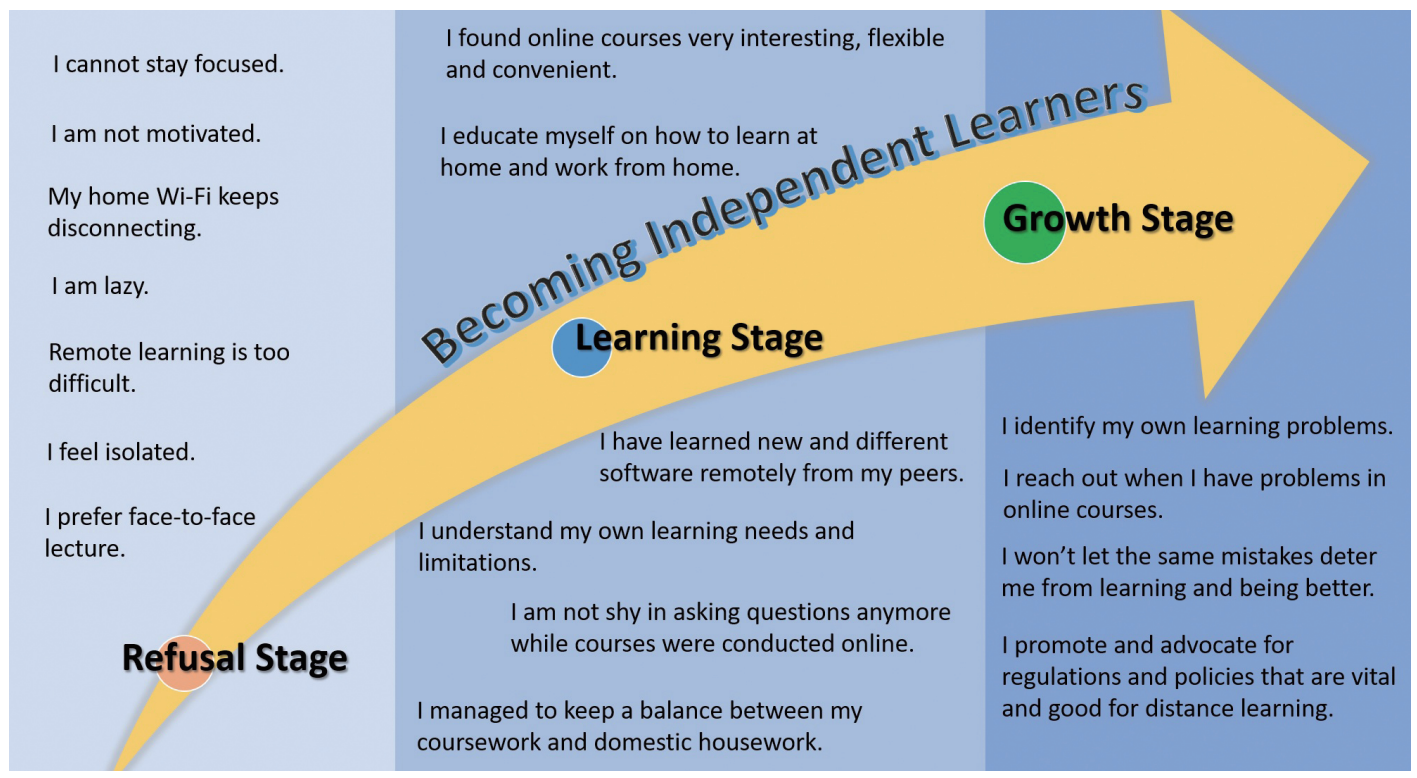

Figure 7. Becoming independent learners during and after the pandemic.

\footnotetext{
${ }^{3}$ This figure was inspired by Andrew M. Ibrahim's (chief medical officer in Healthcare for HOK in the United States) mental model, which appeared on Twitter in June 2020.
} 
The students' responses to the question of "what was/were the biggest challenge(s) you encountered this semester? Any solutions?" are summarized in the refusal stage below. As Figure 7 demonstrated, the refusal stage involves the conflict between autonomy and doubt, and emotions like fear, a sense of guilt and inferiority over their self-initiated online learning activities during the pandemic. This is also reflected in responses to the initial survey that students were not comfortable with the virtual classrooms and preferred face-to-face interaction. As our students engage more in social interactions with academic activities such as in-class group discussions, weekly exercises and projects, and group presentations, etc., they would enter the learning stage to develop a sense of pride and accomplishment in their abilities to work online and independently with others. The learning stage in Figure 7 below vividly illustrates the significant reasons why some of our students are highly satisfied with all the online courses they had remotely from home. At last, the growth stage positively shows us that, according to the responses we collected from the question of "how to improve the teaching qualities if we have to stay online again next semester? What are your suggestions to your course instructors, teaching assistant, and other students", it is apparent that the students have gained positive exposure to a newer paradigm to utilize online educational resources and to stimulate self-learning abilities among themselves during lockdown. In general, we believed that the growth stage is crucial among the students, particularly in forging a strong sense of identity to feel independent, secure, and ready to face and find the future direction in their studies and lives during the pandemic.

\section{Conclusion}

The COVID-19 pandemic has had a severe impact on higher education as universities shut their doors in response to lockdown measures. While these lockdowns have interrupted conventional classroom learning, the coronavirus pandemic also empowers and quickens students' journey toward online education and independent learning. By comparing the results of two surveys, as concluded in Figure 7, it is not inappropriate to infer that online learning has brought us a new paradigm shift in higher education. While technology is a significant ingredient in this paradigm shift, we must not forget that the course syllabi, assessment methods, and learning outcomes must reflect the need for independent learning. In this light, our school, teachers, and students must not only be concerned about getting high grades but 
encourage collaborative and self-learning among the students. One of the most critical issues for adopting this new mode of teaching and learning is online assessment and examinations. The new mode of teaching and learning, however, must be implemented with meticulous planning and experimental learning that involves each academic division, Academic Registry, and IT department over the efficiency and accountability of online assessments for all UIC courses after the Covid-19 crisis subsides. More importantly, we must take care of the weak students, especially those who are suffering academically, psychologically, and financially etc., since their academic journey should also be made equally rewarding during the pandemic.

\section{Acknowledgments}

This study is financially supported by the BNU-HKU United International College Research Grant [grant number R202047] and the Education Department of Guangdong Province under the scheme of University Innovation and Enhancement Project [grant number 2018WTSCX193]. The authors would like to express their sincere gratitude to two anonymous reviewers for their precise and thoughtful comments. The authors would also like to extend appreciation to all the students who completed the questionnaires. Finally, the authors are highly thankful to Clare Zhu for her contribution to this work.

\section{References}

Andrew M. Ibrahim MD, MSc [@AndrewMIbrahimIbrahim] (n.d.). Home [Twitter page]. Twitter. https://bit.ly/370zj8eBabbie, E. (2007). The practice of social research (11th ed.). Wadsworth Publishing Company.

Cheese, P. (Ed.) (2008). Netting the net generation. https://bloom.bg/3qIZCaH

Lebedko, G. M. (2014). Globalization, networking and intercultural communication. Intercultural Communication Studies, 23(1), 28-41. https://bit.ly/3qKqbMz

Pfister, D. S., \& Soliz, J. (2011). (Re)Conceptualizing intercultural communication in a networked society. Journal of International and Intercultural Communication, 4(4), 246251. https://doi.org/10.1080/17513057.2011.598043

Shuter, R. (2012). Intercultural new media studies: The next frontier in intercultural communication. Journal of Intercultural Communication Research, 41(3), 219-237. https://doi.org/10.1080/17475759.2012.728761 


\section{Wei Chin Wong \& Xun Wang}

\section{Appendix 1}

\section{Initial questionnaire}

Students' Feedback and Opinions about the Online Courses in UIC during a Pandemic (Spring Semester 2019/2020)

By Dr. Wong Wei Chin

Note: This survey examines and compares students' experiences at the beginning and the end of online teaching (of their courses with Dr. Wong Wei Chin) during the Week Zero (February 10 to 14,2020) in the Spring Semester 2019/2020. Thank you for having your feedback.

1. What is your current location?

2. Describe your experience in general about the online courses in UIC.

3. What problems, if any, are you having the online environment?

(Note: You may select more than one answer).

Connectively

$\square$ Uploading

$\square$ Time lag in the live broadcast

$\square$ Access to IT support

$\square$ Other

4. Which video conferencing software are you preferring?

(Note: You may select more than one answer).

Panopto Cloud

Zoom

All of above

$\square$ None of above

The End, Thank You! 


\section{Appendix 2}

\section{Second-stage questionnaire}

Students' Feedback and Opinions about the Online Courses in UIC during a Pandemic (Spring Semester 2019/2020)

By Wong Wei Chin and Wang Xun

Note: This survey examines and compares students' experiences at the beginning and the end of online teaching (of all their courses) during a COVID-19 pandemic in Spring Semester 2019/2020. Thank you for having your feedback.

\section{I) Particular Information}

1. What is your name? (For example: David Zhang):

2. Which year are you in your studies in UIC?

$\square$ Freshman (Year-1)

$\square$ Sophomore (Year-2)

$\square$ Junior (Year-3)

$\square$ Senior (Year-4)

$\square$ Postgraduate

3. What is your gender?

$\square$ Male

$\square$ Female

4. Which division do you belong to?

\section{DBM \\ DST \\ DHSS \\ DCC}

$\square$ Other. Please specify:

5. I would like to keep my feedback as:

\section{Open}

$\square$ Anonymous 


\section{Wei Chin Wong \& Xun Wang}

\section{II) Specific Questions}

1.Where did you live while you attend the online courses this semester?

$\square$ Zhuhai City

$\square$ In Guangdong Province (Except Zhuhai City).

$\square$ Out of Guangdong Province but live in Mainland China. Please specify

which province you are in if you live in Mainland China:

Hong Kong/Macao/Taiwan

$\square$ Overseas Country. Please specify which country you are in if you are outside China:

2. Which online teaching platform(s) are you using in this semester? (Note: You may select more than one answer).

$\square$ iSpace/Moodle

$\square$ Panopto Cloud

$\square$ Zoom

$\square$ WeChat Work

$\square$ Other. Please specify:

$\square$ None of the above.

3. a) Which online teaching platforms are you preferring this semester? (Note: You may select more than one answer).

$\square$ iSpace/Moodle

Panopto Cloud

WeChat Work

Other. Please specify:

$\square$ None of the above.

b) Why? Please briefly explain:

4. a) Did you encounter technical problems, if any, with the following online teaching platform(s) throughout the semester? (Note: You may select more than one answer).

$\square$ iSpace/Moodle

Panopto Cloud 


\section{WeChat Work}

Other. Please specify:

None of the above.

b)What problems, if any, are you having with the above-mentioned online teaching platform(s)? (Note: You may select more than one answer).

Connectivity

$\square$ Uploading

$\square$ Time lag in the live broadcast

Access to IT support

$\square$ Other. Please specify:

c) What was/were the biggest challenge(s) you have encountered in this semester? Any solutions?

5. a) Overall, how much do you like the online courses that you enrolled in this semester? Please rate according to the following scale.

(Note: Please choose one answer only).

$\square$ Highly unsatisfactory

$\square$ Unsatisfactory

$\square$ Moderately satisfactory

$\square$ Satisfactory

$\square$ Highly satisfactory

b) Why? Please explain briefly.

6. What was/were the most memorable learning experience(s) you had in this semester?

7. How to improve the teaching qualities if we must stay online again next semester? What are your suggestions to your course instructors, teaching assistants, and other students?

The End, Thank You!

Received July 14, 2020 